\title{
Emergency Medicine in the Czech Republic
}

\author{
Jiri Pokorny \\ POMAMED, Prague, \\ Czech Republic
}

\section{Introduction}

The history of out-of-hospital emergency medicine begins many centuries ago. Efforts to help patients have been made by mankind for a long time. In principle, two approaches to providing professional medical assistance can be identified; either with medical help called to the affected person, or the person involved being transferred either to a shaman, a physician, or to a medical center. The story of in-hospital emergency medicine begins with the setting up of facilities designed to take care of and treat those affected in hospitals. The traditional model of provision of emergency care includes outpatient departments related to the individual branches of medicine. The 1960s saw the building of the first emergency departments in the United States (2).

Pre-hospital emergency care has a long-standing tradition in this country. The predecessor of Prague's emergency medical service, referred to as the Prague Volunteer Protection Unit, was established as early as 1857 making it, together with the Budapest-based predecessor of emergency service, to the oldest emergency units within Europe. Just as in many other countries, the utmost priority of the emergency service was to transfer the patient to hospital faster and in a more patient-friendly manner than before. While both world wars, and the Korean and Vietnam wars, brought immense suffering to millions of people, they helped mankind make major progress in their knowledge regarding the provision of emergency care and management of trauma-related shock, as well as clearly showing the advantages of early acute surgery. Military experience has necessarily translated into the provision of emergency care outside the battlefield. Additionally, provision of emergency care had to reflect new insights into the pathophysiology and management of various types of shock, intoxication, coronary heart disease, stroke, and so on.

It should be noted here that modern history of emergency medicine in the Czech Republic began to unfold in what was formerly referred to as the Czechoslovak Republic, as a country founded in 1918 and inhabited by the Czech and Slovak nations until its breakup into the Czech Republic and Slovakia in 1992.

\section{Milestones of emergency medicine in the Czech Republic}

Several milestones can be identified in the evolution of emergency medicine in the Czech Republic including, in particular: 
- $\quad$ Building up a service for transferring patients to health care facilities;

- The founding of coronary care units and first departments of anesthesiology/ resuscitation;

- The 1968 Soviet-led invasion of Czechoslovakia making hundreds of experienced physicians and nurses flee the country;

- A 1974 decree of the Czechoslovak Ministry of Health dividing health care into several levels to reflect patients' needs and requiring the setting up of emergency medical units across the country (2);

- November 1989, the fall of the Communist regime and the Iron Curtain, liberalization of societal and economic life and, subsequently, the entry of private entities into the health care sector;

- A 1992 decree of the Czech Ministry of Health (No. 434/92 et seq.) governing emergency medical service (EMS);

- The decision by the Health Minister, Ivan David, in 1998 to make emergency medicine a separate branch of medicine requiring each future specialist to pass a board examination (6);

- Widespread floods in 1997 and 2002 (the so called "thousand-year water") and the 9/11 terrorist attacks in the USA in 2001;

- The economic crisis which hit the world in 2008;

- The year 2011 making the Emergency Medical Service a law.

According to a concept developed by the Czech Ministry of Health and published in 1974, patients are provided health care at different levels $(1,2)$. The top level of differentiated medical care is resuscitation care in patients developing failure of one or several organs. Originally, this type of care should be provided to patients by multidisciplinary teams at units of anesthesiology/resuscitation; also later at newly formed departments of anesthesiology/resuscitation. The next level below is intensive care provided to patients who have not yet developed failure of vital function but are at risk of this. Intensive care is provided at intensive care units (ICUs), set up predominantly at departments related to the respective branch of medicine, thus giving rise to ICUs of internal medicine, neurology, surgery, urology, gynecology, orthopedics, otorhinolaryngology, and psychiatry as well as pediatric ICUs at departments of pediatrics. These units gradually evolved into subspecialty ones, both within internal medicine and other branches of medicine, to become coronary care and metabolic care units, ICUs of neurosurgery, spondylosurgery, spinal, neonatal, and pre-mature baby ICUs, and so on. The historical division of differentiated care into resuscitation units and ICUs is no longer applicable as many ICUs provide resuscitation care in addition to intensive care, while standard care is provided in standard hospital wards. An extension to standard health care is long-term care, and rehabilitation care, as well as care provided at spa facilities. The lowest level of differentiated care is represented by symptomatic care available to those patients who cannot be cured by state-of-the-art medicine.

\section{Building of the system of emergency care in the Czech Republic}

Up to the 1970s, pre-hospital emergency care was provided by the general practitioner emergency service (called LSPP, in Czech) in most regions of the country. Originally, this 
state-run type of care was intended to provide pre-hospital emergency care for citizens in the off-hours when general practitioners or outpatient specialists were unavailable. Physicians on duty would visit not only those who could not be transferred to LSPP offices (whatever the reason) but also had to attend to the most serious cases including persons involved in road accidents, those developing spasmodic conditions, unconscious persons, and those requiring resuscitation. Additionally, their duties included inquests into the cause of death. The professional standard of care depended not only on the erudition and skills of the physician on duty but, also, on the availability of equipment to provide emergency care (and its condition). Another important consideration was the driver on duty on that particular day. Ideally, EMS ambulance crews included two members but the driver's only responsibility was to take the physician to the scene of emergency and back, with any other assistance depending solely on the driver's good will and willingness. In cases where the patient's condition required emergency care and the other member was only "a driver", emergency care was provided exclusively in an impromptu manner by the physician with the outcomes necessarily being such. For a long time, LSPP served as a backup to EMS called in cases requiring care for several patients at a time, or when an EMS ambulance was currently unavailable, e.g., because of a mechanical defect, or in cases requiring secondary transfer in a system where only a single EMS ambulance with a physician was operating within the whole region. Upon the setting up of a network of EMS ambulance stations, the list of duties of emergency service became somewhat shorter, soon to be currently trimmed even more and transformed. If serving properly and performing visits to outpatients, then this type of medical care attends to those developing conditions which, while not posing an immediate threat to life, could result in injury to the patient if deferring care, or if making the patient unnecessarily suffer for a prolonged period of time (e.g., intense pain of the spine). Whilst only restricted to shorter working hours in some areas, LSPP has been completely discontinued in other. According to health care managers, health care should be provided by both EMS and emergency departments, as well as by outpatient departments of hospitals instead of LSPP.

In the Czech Republic, out-of hospital emergency care is also provided by:

- General practitioners and outpatient specialists in their offices with, additionally, general practitioners during their visits to patients, particularly where an EMS ambulance is unavailable at the moment or in cases where the patient's condition deteriorates during the visit.

- Specialist emergency (rescue) units in cases where management of the patient's condition requires, in addition to medical knowledge and expertise, additional training and skills not expected from general health care professionals, such as those of fire fighters, mountain rescue service teams, water rescue service, mining rescue service, cavers, and dog trainers.

- $\quad$ The Czech Red Cross, responsible in particular for supervising compliance with safety rules at major cultural and political events as well as during disasters.

- A variety of private entities providing usual or, as an exception, also less demanding emergency, well paid, care to well-off patients, mainly to rich foreigners.

The above decree issued by the Ministry of Health in 1974 became the basis for setting up a network of EMS throughout the Czech Republic. The system selected for emergency care 
provision is the so-called French-German one whereby the EMS ambulance crew includes a physician. The reasons for this care, for one thing, traditional ones, with the rationale that if the physician makes decisions in cases involving no risk of a delay in care - then they should logically also establish the diagnosis and treat patients in a much more serious condition. The medical-based reason for the decision was progress in medicine. It is now generally accepted that what actually matters is not to get the patient to hospital "as soon as possible" but to get them there alive. A critical consideration in emergency medicine is often truly a matter of life and death, i.e., timely provision of invasive procedures already when initiating treatment "on the spot", be that resuscitation involving clearing of the airways and early defibrillation, aggressive management of an anaphylactic reaction, or draining of a tense pneumothorax. The building of the emergency service system has been under the supervision of departments of anesthesiology and resuscitation care ever since 1974 (4). Much of the credit for the current EMS in the Czech Republic goes to anesthesiologists. However, those "going out" to attend to patients or the injured at that time included not only anesthesiologists but, also physicians serving at other departments as assigned by the hospital director. The list of enthusiasts laying, under not easy conditions, the foundations of this country's modern emergency service should by no means fail to include Mikeš, Dostál, Hasík, Novotný, Štětina, and Ždichynec, to mention just a few (5). There is little doubt that the concept of building the EMS network, as conceived by the ministry of health, has distinct advantages but, also, a host of drawbacks. It was not a rare occurrence that shifts in emergency service were assigned to junior physicians at the department or even physicians who had not passed board examinations yet, with the rationale being that fulltime and senior physicians had "more important commitments" at their departments. Likewise, most hospitals did not then have the lightweight and portable PR-35 handheld transceivers, so physicians listed for EMS on a particular day were told to go to an emergency via regular hospital phone extensions not allocated for that purpose. No wonder then that 5 or 10 minutes were lost before locating and waiting for the physician on duty, and the time lost could not be made up however short the trip to the patient was. Accordingly, the fate of patients often depended not only the seriousness of the emergency but, also, on the department and the physician on duty on that particular day. In the decision-making process about the purchase of medical technology, departments and wards were most often given priority over the emergency service as heads of departments were invariably given priority over physicians in charge of the emergency service in the respective area. Given the need to solve the problems and to coordinate the service of rescue teams, Jiři Pokorný sr, the opinion leader in anesthesiology and resuscitation, established an Advisory Board headed by František Ždichynec, director of Prague's Emergency Medical Service until 1990. The Advisory Board included not only chief physicians of EMS units but, also, a number of accomplished experts in other branches providing emergency care. Thanks to rational argumentation when negotiating with the state bodies, a number of achievements were made. The most important of these was the centralized purchase of a 100 fully-equipped Renault Master ambulances, giving the rescue crew the opportunity to use technology they were aware of only when perusing journals and exhibitions until then. Although this was a major qualitative improvement across much of the territory of what was Czechoslovakia at that time, the number of EMS ambulances was not sufficient for all 
stations, a fact often resulting in conflicts. In some districts, hospital managers went as far as to dismantle the built-in equipment and rather install it in their hospitals. It was these facts that apparently largely contributed to a situation whereby, in the turbulent years following the so-called Velvet Revolution (1989), proponents seeking complete independence of the EMS eventually had their say. However, not all experts were in favor of such a concept (Hora, Pokorný jr). Upon the resignation of Ždichynec as Head of the Advisory Board, the body was taken over by a group of radical proponents of the concept of independence of the rescue services and their detachment from hospitals as the only possible solution. The legislative basis for complete independence of the rescue services was decree 434/92 Coll. Of Laws on EMS. Thus, after less than 20 years of fruitful cooperation, the year 1993 saw the definitive separation of out-of-hospital emergency care from in-hospital emergency care. On the one hand, the independence of rescue services made it possible to complete the creation of a network of EMS ambulance stations, independent health care dispatch units, markedly improved equipment of ambulance vehicles, and improved organization. As a distinct bonus, the independence of the emergency service also facilitated the creation of an integrated rescue system (EMS, firefighting service, and police). The trauma but, also, whole disaster plans of hospitals and districts were re-defined accordingly. On the other hand, this also resulted in the emergency services moving to facilities outside hospitals (most often shared with firefighting units) as well as in severing the "professional links" of the EMS staff to hospitals with all the negative implications.

The air medical emergency service went into pilot operation in Czechoslovakia in April 1987 in Prague. The medical team consisted most often of a physician and a rescuer. While, in indicated cases, transportation of patients by air is no doubt beneficial for the patient, it is extremely costly and its availability is not infrequently limited by the weather.

From time to time, there have been attempts to provide at least basic emergency care in busy downtown Prague by paramedics riding motorcycles. In the large majority of test operations, the rescuer was a paramedic. However, this type of EMS never gained widespread acceptance to actually go into operation - not even with weather permitting. Currently, tests are underway in central Prague to drive the paramedic to the site of an emergency in a minicar.

\section{Hospital-based emergency care}

The importance of the quick availability of emergency medical care is clearly highlighted not only by warfare experience. The traditional hospital-based pattern of admitting patients and the injured was simply no longer able to meet the demands of modern medicine. The biggest drawback of this concept has turned out to be what could be referred to as the "admission vacuum", i.e., the period of time from patient arrival at a hospital and the time point at which (the necessary) care begins to be instituted by a fully qualified and experienced staff in facilities adequate to and specifically assigned for this purpose, with continued hospital-based emergency care. The first "resuscitation ward" was founded, thanks to the foresight of Hugo Keszler as early as 1953 in a department of experimental surgery in Prague. The first department of anesthesiology and resuscitation for "field" patients opened in downtown Prague thanks to the enlightenment of Prof. 
Špaček, Director of the Institute for Clinical and Experimental Medicine, as early as 15th February 1965 at Prague's Na Františku Hospital, which became the center for the training of physicians and nurses. Facilities for the admission and early management of the most serious cases were also being founded in out-of-Prague hospitals. They were rooms in the vicinity of EMS ambulance arrival points so as not to lose time by transporting the patient along hospital corridors or waiting for lifts (e.g., in Kladno and Mladá Boleslav, districts towns close to the capital). However, these were actually not "emergencies" as we perceive them in the Czech Republic today, or even Anglo-American style "emergencies" but, rather, admission rooms of specialist departments of resuscitation with a "high threshold" of patient admission.

As a legacy from its Communist era, the Czech Republic inherited an absolutely rational division of hospitals from level I to III facilities, which was a source of envy - at that time of managers organizing health care in so-called developed nations. Type I hospitals of local importance and running just several departments provided health care only in the basic branches of medicine. More important for providing emergency care were type II hospitals serving a district catchment area and having more departments including specialist ones. In addition to attending to patients from their catchment area, these hospitals served as centers offering professional care and experience to type I hospitals. Top level care was available at type III hospitals, that is, regional facilities and university (teaching) hospitals. The extent of care possibly provided by each particular hospital was clearly specified according to its "classification". Interestingly, this division was similar to the pattern of facilities providing traumatology care in the USA. Regrettably, the Velvet Revolution introduced, as a reaction to the countless restrictions by the former regime, the "pendulum" principle whereby any regulation was harmful in the hope that all problems would be eliminated by the "invisible hand of the market". As a result, and quite paradoxically, a brand-new and well-equipped, five-bed department of resuscitation opened in a community (formerly Type I) in Sedlčany (a small town about $70 \mathrm{kms}$ south-west of Prague) in the 1990s whereas one of the country's largest health care facilities - Thomayer University Hospital in Prague - did not have its own resuscitation department until 2001. Until then, patients urgently requiring resuscitation care had to be transferred by EMS ambulances and by air to facilities outside Prague, not infrequently exactly to the hospital at Sedlčany. Some regulation of the spectrum of procedures available was only introduced in recent years, mostly due to the restriction of the list of procedures reimbursed by health care insurance companies.

\section{NEZAS and the birth of emergency departments}

A most interesting - and to date little appreciated - experiment was the attempt by František Ždichynec, the last pre-Velvet Revolution director of Prague's EMS to ensure hospital-based backup and feedback to their physicians and nurses to maintain their erudition and continuity of pre-hospital and in-hospital emergency care. Ždichynec managed to acquire a Prague-based hospital called NEZAS catering to top Communist party and other top-level officials. The hospital was intended to become the center for the management of acute conditions of all branches of medicine including management of multiple trauma. It should have been the referral facility for a major proportion of patients 
needing emergency care in Prague. The idea of a hospital specializing in the treatment of acute conditions of all branches was not new, as similar hospitals were already in operation not only in Western nations but, also, in e.g., Sofia, Bulgaria, whereby full-time hospital physicians and those on duty as EMS members serve on a rotation basis. Specifically, after several months in a ward (depending on their specialty) and in the emergency department, they were to replace their colleagues serving as standby EMS members. The most experienced physicians were on duty in the air rescue service. As a result, the hospital set up the most unique unit of centralized admission as one of the first in what was then Czechoslovakia. The central out-of-hospital emergency department included two observation beds. The intention was to create a department, using the Western world pattern as a model, providing smooth and problem-free continuous provision of prehospital and in-hospital emergency care without the "admission vacuum". Using current terminology, the centralized admission system served as a high threshold (exclusively for the most critical cases) and, also, as a "shelter" for patients who, while requiring emergency care, could not be referred to other health care facilities. The problem was that a high proportion of these "difficult to refer" patients were also the most critical ones as they necessitated not only a specialist ward with mechanical ventilation and flawless monitoring but, also, an experienced team of physicians and nursing staff. These patients included those in the early stages of serious conditions or critical injury or, possibly, resuscitated patients who were by far not in a stable condition. At that time, Prague was coping with a lack of hospital beds with mechanical ventilation. It was not a rare occurrence that patients admitted to an emergency department were subsequently transferred, by car or by air, to various departments of anesthesiology/resuscitation within the Central Bohemia region and, occasionally, to hospitals even farther away. From $03.30 \mathrm{pm}$ to $07.00 \mathrm{am}$, the centralized out-of-hospital emergency department worked both as a "low-threshold" one serving as an admission, treatment and observation center normally referred to specialist outpatient departments in the working hours, and patients requiring intensive and resuscitation care. It was just the pattern of work within and without the working hours that made the centralized out-of-hospital emergency department of NEZAS markedly different from Western-type emergency departments. Still, it can be reasonably claimed that it belonged to those most resembling the Anglo-American model of these departments. It turned out to be a good concept to place observation beds and one EMS ambulance station with a physician available direct in the hospital. Regrettably, the original idea actually never came into life. In addition to the "human factor" bursting out after the resignation of Ždichynec, the founding father of the concept, from the post of director, in the spring of 1990, there were objective reasons. NEZAS was a small facility and already in the 1990s with inadequate capacity, small numbers of departments, beds, limited capacity and throughput. The availability of consultations, not to mention super-consultation, was suboptimal. A major drawback of the hospital was its location of a residential, sparsely inhabited area, and a minimal natural catchment area of patients. Arrival times both from downtown Prague and most of the city were fairly long. Its location atop a hill with a fairly steep slope proved an additional disadvantage when there was snowfall. The helipad was by far most inadequate and there was even an accident with the helicopter damaged when landing. It was perhaps these reasons which contributed to the fact that, after the completion and opening of a brand-new section of Motol University Hospital with hundreds of beds and incomparably better 
location, NEZAS lost its last reason to exist to become a private rehabilitation facility. Perhaps the main lesson drawn from the times of the NEZAS centralized out-of-hospital emergency department is that work in such a department is a major bonus for physicians and nurses involved in emergency care. Still, emergency departments should be set up primarily in large hospitals with well-equipped diagnostic capabilities, a wide range of specialties providing emergency care, and an adequate number of standard and specialist beds including observation ones.

The era after the Velvet Revolution saw, in the 1990s, the setting up of additional emergency departments, unfortunately, in a quite uncoordinated manner, under various names, with differently set thresholds or specialties for admitting patients. With no clear definition of an emergency department, it cannot be reasonably determined how many such facilities - and at what level - currently exist within the country*. In some cases, emergency departments attend exclusively to patients with internal diseases, as is the case of the Department of Medicine III of the Prague-based General University Hospital. Only several departments are of interdisciplinary nature. A most atypical pattern of providing early in-hospital emergency care can be seen in the Prague-based Motol University Hospital, the country's largest. Admitted patients requiring emergency care are divided into several streams. The most serious cases with failing vital functions are transported by EMS direct to two resuscitation units of the Department of Anesthesiology/Resuscitation. A proportion of patients in need of intensive care is referred direct from the field to metabolic or coronary care units. All trauma patients not admitted to the resuscitation units go past the emergency department and are brought to an outpatient trauma unit. Some patients are treated directly at outpatient units of specialties available in the particular hospital. Except for outpatient departments of internal medicine, neurology, and orthopedics, all specialist outpatient departments take care of patients on a 24/7/52 basis. The remaining stream comprises mainly patients presenting with acute internal or neurological conditions, intoxicated individuals, those with acute lung conditions, altered consciousness, and other conditions of unclear etiology. These patients are attended to at the emergency department. Unfortunately, those transferred to the emergency department include drunk individuals and the homeless, who take the beds necessary for true patients. The unit has only seven beds and no observation beds. Moreover, in addition to the in-hospital emergency department, emergency service is available (between $7 \mathrm{pm}$ and $7 \mathrm{am}$ ) for those presenting with milder conditions in separate rooms one floor above. This emergency service was set up after several LSPP had been discontinued within the university hospital's catchment area. The emergency admission unit is operated by full-time physicians, out-of-hospital physicians, and EMS physicians. A proportion of these physicians have passed the board examination in emergency medicine, while others are just preparing for the examination. The remaining physicians are board-certified in a basic branch of medicine, most often in internal medicine and anesthesiology/resuscitation. In the section providing care to patients with milder conditions, there are mainly general practitioners and out-of-hospital physicians.

\footnotetext{
* Answer from the Ministry of Health to the author's query
} 


\section{Emergency medicine becomes a full-fledged specialty}

The separation of the EMS from the specialty of anesthesiology/resuscitation led to the establishing of the Society of Pre-hospital Emergency Care and Disaster Medicine as a member of the Czech Medical Association of J. E. Purkyně. Training has been provided since 1992 by the Chair of Pre-Hospital Emergency Care and Disaster Medicine of the Postgraduate Medical School, later re-named to become Chair of Emergency Care and Disaster Medicine.

In 1998, the then Minister (Ivan David) established emergency medicine as a subspecialty. This made the Czech Republic the 7th European country with emergency medicine acknowledged as a fully-fledged medical specialty. The professional society is currently named the Society of Emergency Medicine and Disaster Medicine of the Czech Medical Association of J. E. Purkyně $(5,6)$. Quite logically, the specialty of emergency medicine should embrace the same areas as is usual elsewhere in the world. Given its historical development in this country, its theoretical and practical parts focus mainly on emergency pre-hospital care and, partly, also on disaster medicine. The emergency admission section was not founded within the professional society until December 2004 to start working in 2005, that is, 7 years after emergency medicine was recognized as a specialty in the Czech Republic.

Kotlyar et al. (3) classify the standard of emergency medicine in individual nations into three groups by the presence or absence of certain features as follows: undeveloped, developing, and developed. In this classification, the Czech Republic belongs to nations with a developed system, being as it is a mixed one with predominant features of the French-German system. There is a nationwide organization, and emergency medicine is a recognized specialty with its own training program. At the time of its recognition, it was a subspecialty for those who had passed board examinations in the five main branches of medicine: anesthesiology/resuscitation, internal medicine, surgery, pediatrics, and general medicine. Today, emergency medicine is also listed as a basic branch. A journal called Urgentni medicina (Emergency medicine, in Czech) is published and distributed on a nationwide basis. The specialty pursues its own special research programs and runs databases as well as training programs in subspecialties. Prague's EMS is among the best in the world. Among other things, it offers training programs and participates in Europeanwide research projects. However, there are not many emergency departments and the overwhelming majority of Czech hospitals do not operate such units at all. In hospitals with these units, they are run in turns by physicians of several specialties. As it is, it is impossible to speak about quality control by comparing the output of individual units. Perhaps the biggest difference as against the Anglo-American system is that many most critical "cases" actually never enter the emergency department and are transferred directly to emergency units of other specialties. In some hospitals, emergency departments are available only for patients presenting with a condition to be managed by an internist while those suffering an injury receive treatment outside the emergency department.

\section{Current status}

Early in-hospital emergency care in the majority of Czech hospitals has been and continues to be provided by specialist outpatient departments related to the branches of medicine 
available in the particular hospital. For a variety of reasons, this traditional system has been in operation, with only minor changes, for dozens of years. Still, the number of emergency departments tends to rise. The first specialists in emergency medicine passed their board examination in 1999, with the number of erudite physicians and paramedics increasing ever since. To date, 18 physicians have qualified as forensic experts in the field of emergency medicine.

The organization of EMS in the Czech Republic resembles the Franco-German system. The most critical "cases" are attended to by a physician arriving by car. In most cases, physicians of EMS do not come in an ambulance, but by car with a driver-paramedic taking them fast to the patient. This system is referred to as a "rendez-vous" one and was introduced, in the Czech Republic, by Prague's EMS Director Ždichynec, in the late 1980s in several points across the capital. Based on the very good experience, the system was quickly adopted by other towns and districts. Since the beginning of the 1990s, emergency medical care has been provided by paramedics, with the extent of their involvement gradually increasing. In Prague itself, ambulance crews without a physician attend to about $80 \%$ of cases. As the pattern of emergency care provision is currently being transformed throughout the country, EMS ambulances also transfer to hospitals patients who used to be examined by their general practitioners during their visits and could often stay home once treated. Not infrequently, their transportation does not require the presence of a physician.

In the Czech Republic, EMS is run and controlled by the state through regional authorities and statutory towns. EMS ambulances are very well equipped. Only a small proportion of emergency care facilities is established and run by private entities such as the Samaritan Association CR, the Sovereign Order of Maltese Knights, and Trans-Hospital. Unlike many other European countries, the Czech Red Cross is not involved in the organization and provision of EMS.

In 1997 and 2002, the Czech Republic was hit by immense floods. There has also been a worldwide increase in the number of terrorist attacks, and interventions in larger numbers of affected persons are on the increase. All this has led to increased preparedness and ability to cope with large-scale disasters and accidents.

A phenomenon challenging all emergency departments is what is referred to as "overcrowding", whereby the capacity of a given department is inadequate to treat patients requiring care within a reasonable timeframe. There are many reasons for "overcrowding": reduction of the numbers of emergency departments, understaffing, increasing reluctance on the part of physicians receiving training in other specialties to get involved in the management of acute conditions, and the risk of malpractice with subsequent legal (and professional) consequences, working under stress and pressure, the need to treat also the homeless, addicts, and so on, and all this in a situation where it is uncertain whether - or how late - they will get paid for their job. In the USA, emergency care is provided by out-ofhospital emergency departments to uninsured individuals (and there are many millions of those). Another major problem is where "to place" patients requiring hospitalization as not all out-of-hospital emergency departments occupy part of a hospital. For reasons easy to understand, hospitals are reluctant to keep vacant beds for "potential" admission of acute 
patients, often without a health insurance policy. These beds may "earn" much more money if used for patients due to undergo, i.e., scheduled for, surgery. In 2004, I was invited to join an international team seeking to address the worldwide problem of overcrowding; admittedly, I was horrified. I was simply unable to believe that the situation in emergency departments could be so upsetting in some hospitals with some patients waiting in corridors for several days for admission to the hospital, and emergency physicians performing classical visits. It had long seemed that overcrowding was not an impending problem for the Czech Republic. However, the repercussions of the worldwide economic crisis, which have resulted in shrinking budgets in the Czech health care system, are beginning to take their toll and overcrowding seems to loom even in this country.

\section{Conclusion}

There is little doubt that out-of hospital and in-hospital emergency care in the Czech Republic is provided at a very good standard, although there is still much room for improvement. In fact, despite some shortcomings, organization of emergency care in this country is among the best in the world. The nationwide system of EMS came into being by a decision of the ministry of health in 1974. In the 1990s, the number of EMS ambulance stations increased substantially and, based on analyses of arrival times in some areas, it continues to rise, though at a slower pace. At present, emergency out-of-hospital care is provided by a total of 14 regional centers of emergency medical care. Decree 434/92 Coll. of Laws sets arrival times across the country at within 15 minutes from the reception of call unless the case requires special attention. The above interval is complied with in $96 \%$ of the territory of the country. Besides, virtually the whole country is covered by air EMS ambulances operating from 10 bases. In terms of EMS ambulance stations, the Czech Republic is among the countries with the most dense network and best accessibility worldwide. These facts actually become most evident when comparing our country with the USA, and are best documented by the experience of a group of American physicians coming as "missionaries" shortly after the Velvet Revolution to visit Prague, the capital of a country they thought of as "Hic sunt leones" uncharted territory; they were left almost speechless when seeing the high-quality system of emergency medical care run in the then Czechoslovakia. Upon departure, the group leader commented "We came here to teach you, now we are leaving educated“.

\section{References}

Drábková et al. Základy anesteziologie (Basics of anesthesiology). 1981 Avicenum, Prague: 8-13.

Drábková et al. Základy resuscitace (Basics of resuscitation). 1982 Avicenum, Prague: 8-10.

Kotlyar S., Arnold J. et al. 2006. Introduction to International Emergency Medicine. Emedicine.com. March 7: 1-11.

Pokorný J., Bohuš O. 1996. Anesteziologie a resuscitace na cestě k oborové samostatnosti v České a Slovenské republice (Anesthesiology and resuscitation on their way to become an independent specialty in the Czech and Slovak Republics.). 1996; Pražská vydavatelská společnost, Prague: 15-62. 
Pokorný J. jr. 2 000. Urgentní medicína: historie, současnost, trendy (Emergency medicine: past, present, and trends.). Trendy v medicíně 2: 93-5.

Pokorny J. 2004. Urgentní medicína (Emergency medicine). Galen, Prague: XV-XI. 


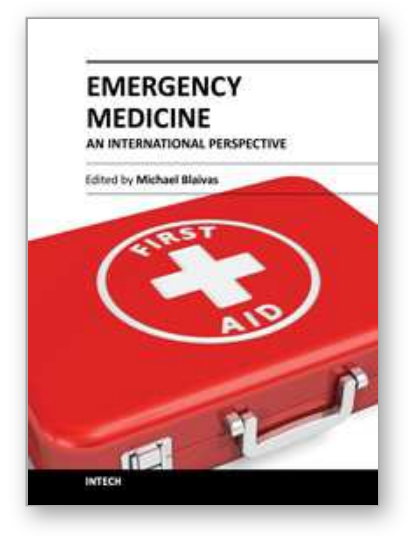

\author{
Emergency Medicine - An International Perspective \\ Edited by Dr. Michael Blaivas
}

ISBN 978-953-51-0333-2

Hard cover, 220 pages

Publisher InTech

Published online 16, March, 2012

Published in print edition March, 2012

Emergency Medicine is an expanding field that has spread beyond the shores of North America and has taken on different characteristics around the world. Although many of the struggles of emergency practitioners are similar, the field and its principles have adapted to local needs and resources. This book seeks to educate readers not only on emergency medicine theory, science and practice, but also reflects that multinational nature of emergency medicine, allowing readers to learn from experiences of others. This diverse group of authors presents a true international view of emergency medicine practice and science that will be educational for any reader.

\title{
How to reference
}

In order to correctly reference this scholarly work, feel free to copy and paste the following:

Jiri Pokorny (2012). Emergency Medicine in the Czech Republic, Emergency Medicine - An International Perspective, Dr. Michael Blaivas (Ed.), ISBN: 978-953-51-0333-2, InTech, Available from:

http://www.intechopen.com/books/emergency-medicine-an-international-perspective/emergency-medicine-inthe-czech-republic

\section{INTECH}

open science | open minds

\section{InTech Europe}

University Campus STeP Ri Slavka Krautzeka 83/A 51000 Rijeka, Croatia Phone: +385 (51) 770447

Fax: +385 (51) 686166 www.intechopen.com

\section{InTech China}

Unit 405, Office Block, Hotel Equatorial Shanghai No.65, Yan An Road (West), Shanghai, 200040, China 中国上海市延安西路65号上海国际贵都大饭店办公楼 405 单元 Phone: +86-21-62489820

Fax: +86-21-62489821 
(C) 2012 The Author(s). Licensee IntechOpen. This is an open access article distributed under the terms of the Creative Commons Attribution 3.0 License, which permits unrestricted use, distribution, and reproduction in any medium, provided the original work is properly cited. 